\title{
OPTICAL AND ELECTRONIC PROPERTIES OF $\mathrm{M}_{2} \mathrm{Si}$ (M=Mg, Ca AND Sr) GROWN BY REACTIVE DEPOSITION TECHNIQUE
}

\author{
JUNHUA HU \\ Graduate School of Science and Technology, Shizuoka University \\ 3-5-1 Johoku, Naka-ku, Hamamatsu, 432-8011, Japan \\ f5645032@ipc.shizuoka.ac.jp \\ AKIHIKO KATO \\ FDK Corporation, 2281 Washizu, \\ Kosai, 431-0495, Japan \\ kato@fdk.co.jp \\ TAIZOH SADOH \\ Department of Electronics, Kyushu University, \\ Fukuoka 819-0395, Japan \\ YOSHUHITO MAEDA \\ Department of Energy Science and Technology, Kyoto University, Kyoto 606-8501, Japan

\section{K.N. GALKIN, T.V.TURCHIN} \\ Institute for Automation and Control Processes of Far Eastern Branch of Russian Academy of Science, \\ 5 Radio St., 690041 Vladivostok, Russia \\ HIROKAZU TATSUOKA ${ }^{\dagger}$ \\ Faculty of Engineering, Shizuoka University, 3-5-1 Johoku, Naka-ku, \\ Hamamatsu 432-8561, Japan \\ Received Day Month Day \\ Revised Day Month Day
}

Single phase $\mathrm{M}_{2} \mathrm{Si}$ (M=Mg, Ca and $\mathrm{Sr}$ ) silicides were grown using Si substrates by thermal treatment of the substrates in the vapors of the metallic sources, M, and the electronic structures and optical property of the silicides were investigated. The electronic band structures of the silicides were calculated using the first-principles total-energy calculation program in pseudopotential schemes

\footnotetext{
† Corresponding author: Hirokazu Tatsuoka

${ }^{\ddagger}$ Faculty of Engineering, Shizuoka University, 3-5-1 Johoku, Naka-ku, Hamamatsu 432-8561, Japan

Phone/FAX: +81-53-478-1099

E-mail: tehtats@ipc.shizuoka.ac.jp
} 
with plane-wave basis functions. The calculated optical reflectance spectra were also deduced from the theoretical band structures, and roughly agreed with the experimental results except for the low reflectance intensity around $2 \mathrm{eV}$. This suggests that the energy band gap of the silicides roughly agree with the calculated values of $0.15,0.31$ and $0.35 \mathrm{eV}$ for $\mathrm{Mg}_{2} \mathrm{Si}, \mathrm{Ca}_{2} \mathrm{Si}$ and $\mathrm{Sr}_{2} \mathrm{Si}$, respectively, within the underestimation of the band gap by the density functional calculation. The optical property of the silicides is also discussed in relation to the morphological structures of the silicides.

Key words: Silicides, Semiconductors, Structural properties, Optical properties and measurements

\section{Introduction}

Recently, semiconducting silicides, which consist of nontoxic and abundant materials, have attracted much attention for their potential to create new classes of environmentally conscious electronics ${ }^{1}$. The II-group half silicides $\mathrm{M}_{2} \mathrm{Si}(\mathrm{M}=\mathrm{Mg}, \mathrm{Ca}$ and $\mathrm{Sr})$ are categorized in this materials group. Magnesium silicide $\left(\mathrm{Mg}_{2} \mathrm{Si}\right)$, which has a anti-CaF $\mathrm{C}_{2}$ type structure with a lattice constant of $0.6351 \mathrm{~nm}$, was reported as a narrow band gap semiconductor with the indirect band gap of $0.6 \sim 0.8 \mathrm{eV} .^{2-5}$ The Mg-based compounds were originally considered to be one of the thermoelectric materials operating above $200^{\circ} \mathrm{C}^{6,7}$ The electronic properties of the silicides have been comprehensively investigated on a theoretical basis. ${ }^{8-13}$

On the other hand, $\mathrm{Ca}_{2} \mathrm{Si}$ and $\mathrm{Sr}_{2} \mathrm{Si}$ have orthorhombic structures with lattice constants of $\mathrm{a}=0.7667, \mathrm{~b}=0.4799, \mathrm{c}=0.9002 \mathrm{~nm}$ for $\mathrm{Ca}_{2} \mathrm{Si}, \mathrm{a}=0.8112 \mathrm{~nm}, \mathrm{~b}=0.5152 \mathrm{~nm}$ and $\mathrm{c}=0.9542$ $\mathrm{nm}$ for $\mathrm{Sr}_{2} \mathrm{Si}^{14,15}$ However, the theoretical results of $\mathrm{Ca}_{2} \mathrm{Si}$ and $\mathrm{Sr}_{2} \mathrm{Si}$ have not been experimentally examined because of the difficulty in growing the silicide layers and bulk crystals. Recently, semiconducting $\mathrm{Ca}_{2} \mathrm{Si}$ and $\mathrm{Sr}_{2} \mathrm{Si}$ were successfully grown on $\mathrm{Mg}_{2} \mathrm{Si}$ bulk crystals and $\mathrm{Mg}_{2} \mathrm{Si} / \mathrm{Si}$ substrates, respectively. ${ }^{16-18}$ However, no experimental optical properties have been reported.

In this study, it was demonstrated that the single phase $\mathrm{M}_{2} \mathrm{Si}(\mathrm{M}=\mathrm{Mg}, \mathrm{Ca}$ and $\mathrm{Sr}$ ) silicides were grown by thermal treatment of the Si substrates in the vapors of the metallic sources, M, and the electronic structures and optical property of the silicides were investigated. The experimental optical reflectance spectra were obtained for the first time for $\mathrm{Ca}_{2} \mathrm{Si}$ and $\mathrm{Sr}_{2} \mathrm{Si}$. In addition, the first-principles analyses of the electronic structures of the $\mathrm{M}_{2} \mathrm{Si}(\mathrm{M}=\mathrm{Mg}, \mathrm{Ca}$ and $\mathrm{Sr})$ are also presented.

\section{Experimental}

$\mathrm{Mg}_{2} \mathrm{Si}$ layers were grown on $\mathrm{Si}(111)$ substrates in $\mathrm{Mg}$ vapor at $500^{\circ} \mathrm{C}$ for 3 or $72 \mathrm{~h}$. The $\mathrm{Mg}$ source and $\mathrm{Si}$ substrates were placed in a loosely sealed container in a vacuum chamber. The $\mathrm{Si}(111)$ wafer was degreased with solvent, etched in HF solution and rinsed with deionized $\mathrm{H}_{2} \mathrm{O}$. Next, the wafers were immersed in a diluted hydrofluoric acid solution ( $\left.\mathrm{HF}: \mathrm{H}_{2} \mathrm{O}=1: 9\right)$, and then dried prior to loading into the vacuum chamber, which was then pumped down to a base pressure of $10^{-3} \mathrm{~Pa}$. No special preheating process for $\mathrm{Si}(111)$ was done before the $\mathrm{Mg}_{2} \mathrm{Si}$ growth. $\mathrm{Ca}_{2} \mathrm{Si}$ and $\mathrm{Sr}_{2} \mathrm{Si}$ were grown at elevated temperatures using $\mathrm{Mg}_{2} \mathrm{Si}$ bulk crystals and $\mathrm{Mg}_{2} \mathrm{Si} / \mathrm{Si}$ substrates under a $\mathrm{Ca}$ or $\mathrm{Sr}$ vapor, respectively. The detailed growth conditions were described elsewhere. ${ }^{16-18}$ The 
reflectance optical spectra were measured in the energy of $1.5-6.5 \mathrm{eV}$ on the Hitach U3010 spectrophotometer with integrated sphere at room temperature

\section{Results and discussion}

The electronic band structures of $\mathrm{Mg}_{2} \mathrm{Si}, \mathrm{Ca}_{2} \mathrm{Si}$ and $\mathrm{Sr}_{2} \mathrm{Si}$ were calculated using the firstprinciples total-energy calculation program ${ }^{19}$ in a pseudopotential scheme with planewave basis functions. It provides electronic structures within density functional theory (DFT) ${ }^{20}$, and the dual-space Gaussian pseudopotentials (norm conserving) and an exchange-correlation functional (local-density approximation) with the parameters tabulated in reference ${ }^{21}$ are employed. The program allows a quick processing to find a solution. The crystalline structure of the silicides and their atomic coordination of the $\mathrm{Mg}, \mathrm{Ca}, \mathrm{Sr}$ and $\mathrm{Si}$ atoms are shown in Refs. 14 and 15. The calculated band structures and reflectance spectra of $\mathrm{Mg}_{2} \mathrm{Si}, \mathrm{Ca}_{2} \mathrm{Si}$ and $\mathrm{Sr}_{2} \mathrm{Si}$ are shown in Fig. 1. It was calculated that the energy band gaps of the silicides were $0.15,0.31$ and $0.35 \mathrm{eV}$ for $\mathrm{Mg}_{2} \mathrm{Si}, \mathrm{Ca}_{2} \mathrm{Si}$ and $\mathrm{Sr}_{2} \mathrm{Si}$, respectively.

The calculated band gap of $0.15 \mathrm{eV}$ for $\mathrm{Mg}_{2} \mathrm{Si}$ in this study agrees with that of $0.12 \mathrm{eV}$ obtained by LDA as well ${ }^{8}$, but it is smaller than that the GW approximation (GWA) results of $0.45 \mathrm{eV}^{8}$ and the empirical PP calculation of $0.53 \mathrm{eV}^{2}$. On the other hand, the optical property of $\mathrm{Mg}_{2} \mathrm{Si}$ has been investigated, and the optical and dielectric constants were analyzed ${ }^{3}$, and the energy band gap of the $\mathrm{Mg}_{2} \mathrm{Si}$ was experimentally obtained as $0.7-0.8 \mathrm{eV}^{4,5}$, which is still more larger than those of calculated values.

This discrepancy is probably due to the underestimation of the calculated energy band gap because the density functional calculation underestimates the energy band gaps of the semiconductors ${ }^{8}$. Namely although the all-electron GWA improves considerably the local-density approximation electronic structure of the semiconductors, it does not always provide the correct energy band gaps for small- and medium-band-gap semiconductors as originally inferred from pseudopotential GWA calculations. The discrepancy between the all-electron and pseudopotential quasiparticle band gaps is mainly traced back to differences between the exchange-correlation matrix elements obtained by the two methods ${ }^{8}$. In addition, most of the small- and medium-band-gap semiconductors GWA does not account for the whole correction of the band gap. The disagreement with the experiment is most probably due to the neglect of the core-polarization interaction and to effects beyond the GWA ${ }^{8}$.

The On the other hand, for the $\mathrm{Ca}_{2} \mathrm{Si}$ and $\mathrm{Sr}_{2} \mathrm{Si}$, Bisi et al. calculated the density of states (DOSs) of $\mathrm{Ca}_{2} \mathrm{Si}$ using the linear-muffin-tin orbital (LMTO) method and concluded that $\mathrm{Ca} 2 \mathrm{Si}$ is a semimetal ${ }^{9}$. It has been reported that the band gap of $\mathrm{Ca}_{2} \mathrm{Si}$ is $1.02 \mathrm{eV}$ within the GWA, whereas its only $0.30 \mathrm{eV}$ within the density functional theory (DFT) ${ }^{10}$. This DFT value is in good agreement with the value of $0.35 \mathrm{eV}$ reported by Migas et al. ${ }^{11}$. In addition, $\mathrm{Ca}_{2} \mathrm{Si}$ is predicted to have a direct band gap of $0.362 \mathrm{eV}$ at $\Gamma$ and $\mathrm{Sr}_{2} \mathrm{Si}$ has a slightly wider direct band gap of $0.402 \mathrm{eV}$ at $\Gamma^{12}$.

On the other hand, the experimental band gap of $\mathrm{Ca}_{2} \mathrm{Si}$ was estimated as $1.9 \mathrm{eV}$ by resistivity measurements ${ }^{22}$. However, it is also reported that $\mathrm{Mg}_{2} \mathrm{Si}, \mathrm{BaSi}_{2}$ and $\mathrm{Ca}_{2} \mathrm{Si}$ are 
reported to be semiconducting with the band gap of $0.77,1.3$ and $1.9 \mathrm{eV}$, respectively ${ }^{5}$, but the author of the recent monograph of semiconducting silicides does not definitely treat the last as a semiconductors ${ }^{23}$ by Y. Imai et al. ${ }^{12}$. In addition, D. B. Migas et al. also reported that one has to be careful with the gap estimates in $\mathrm{Ca}_{2} \mathrm{Si}(1.90 \mathrm{eV}), \mathrm{Ca}_{2} \mathrm{Sn}$ $(0.90 \mathrm{eV})$ and $\mathrm{Ca}_{2} \mathrm{~Pb}(0.46 \mathrm{eV})$ by resistivity measurements in Ref.22 because of the problems in the crystal structure determination. Although the GWA sometimes leads to a slightly underestimated interband transition for semiconductors ${ }^{10}$, it is considered that the band gap of $1.90 \mathrm{eV}$ of $\mathrm{Ca}_{2} \mathrm{Si}$ is unexpected.

(a)

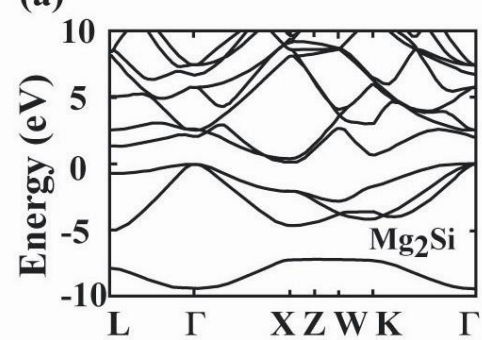

(b)

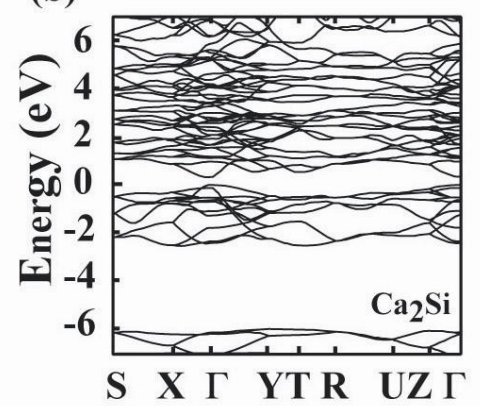

(c)

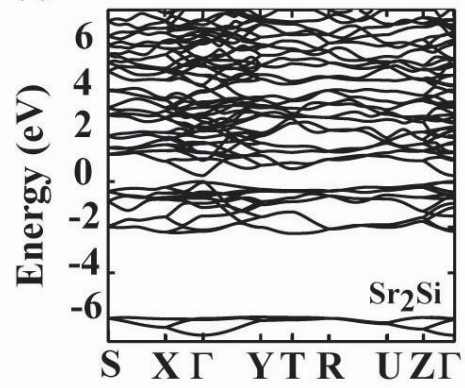

(d)

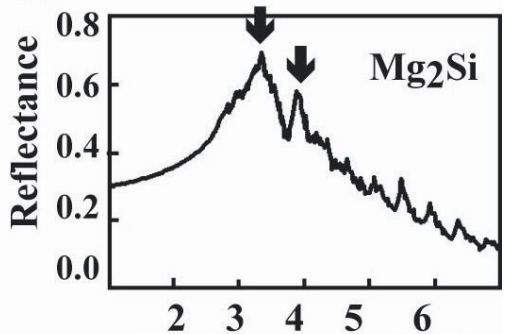

Photon energy $[\mathrm{eV}]$

(e)

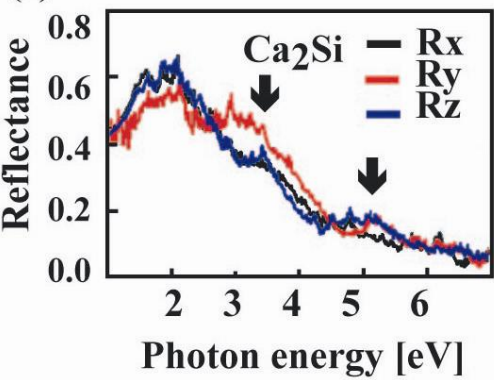

(f)

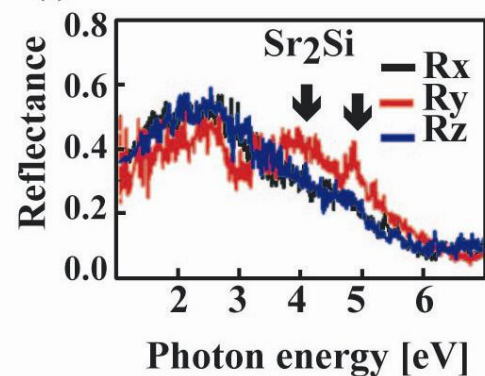

Fig. 1. Calculated electronic band diagrams of (a) $\mathrm{Mg}_{2} \mathrm{Si}$, (b) $\mathrm{Ca}_{2} \mathrm{Si}$ and (c) $\mathrm{Sr}_{2} \mathrm{Si}$. In addition, the calculated optical reflectance spectra of (d) $\mathrm{Mg}_{2} \mathrm{Si}$, (e) $\mathrm{Ca}_{2} \mathrm{Si}$ and (f) $\mathrm{Sr}_{2} \mathrm{Si}$ are also shown. 


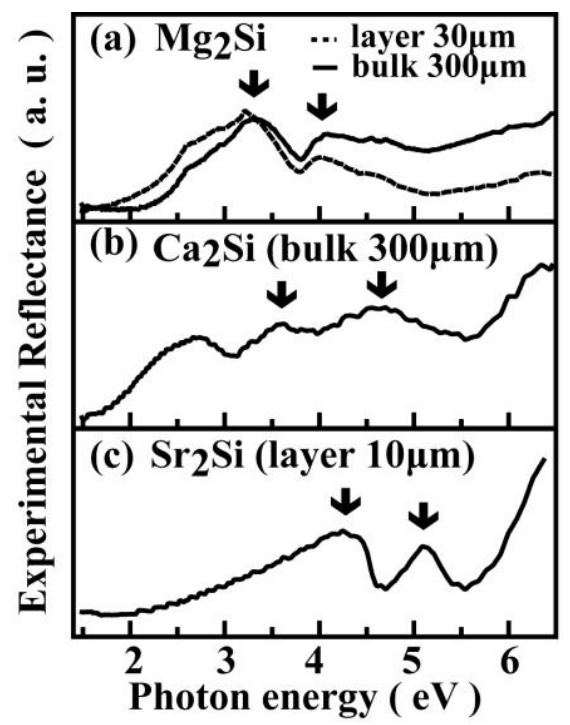

Fig.2 Experimental optical reflectance spectra of (a) $\mathrm{Mg}_{2} \mathrm{Si}$, (b) $\mathrm{Ca}_{2} \mathrm{Si}$ and (c) $\mathrm{Sr}_{2} \mathrm{Si}$.

In Fig. 1, the calculated optical reflectance deduced from the calculated electronic band diagrams are also shown. The arrows show the characteristic features of the spectra. The features of the reflectance peaks of $\mathrm{Mg}_{2} \mathrm{Si}$ have already been discussed well, and the interband transitions are considered to be due to $\Sigma_{4}, \rightarrow \Sigma_{1}, \Delta_{5} \rightarrow \Delta_{2}$ for the $3.3 \mathrm{eV}$ peak, and $\mathrm{L}_{3}{ }^{\prime} \rightarrow \mathrm{L}_{3}, \Lambda_{3} \rightarrow \Lambda_{3}, \Delta_{5} \rightarrow \Delta_{1}$ for the peak at $3.7 \mathrm{eV}[2,8]$. However, few discussions about the interband transition have been made for $\mathrm{Ca}_{2} \mathrm{Si}^{13}$ and $\mathrm{Sr}_{2} \mathrm{Si}$. However, assuming that the interband transition energies of 3.45 and $3.18 \mathrm{eV}$ calculated using the GWA give more accurate values; the reflectance peak near $3.5 \mathrm{eV}$ for $\mathrm{Ca}_{2} \mathrm{Si}$ is considered to be due to $S_{\mathrm{v}} \rightarrow S_{2 c}$ and $Z_{8 v} \rightarrow Z_{2 c}$ transitions. ${ }^{13}$

Figures 2(a), (b) and (c) show the experimental optical reflectance spectra for $\mathrm{Mg}_{2} \mathrm{Si}$, $\mathrm{Ca}_{2} \mathrm{Si}$ and $\mathrm{Sr}_{2} \mathrm{Si}$, respectively. The experimental optical property well agrees with the

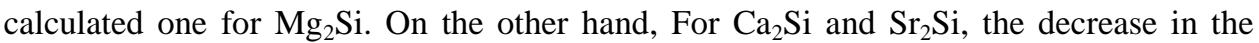
amplitudes in the reflectance spectra of $\mathrm{Ca}_{2} \mathrm{Si}$ and $\mathrm{Sr}_{2} \mathrm{Si}$ are observed in the range around $\sim 2 \mathrm{eV}$ or less in Figs. 2(b) and (c). However, the characteristic features of the spectra in the higher energy range shown by the arrows well agree with the calculated spectra. The decreases in amplitudes in the reflectance spectra in the range of $\sim 2 \mathrm{eV}$ or less are related to the contribution of light scattering at the grain boundaries and inter-granular silicides characterized by different density of states. ${ }^{24}$ Furthermore, the extinction coefficient of the silicide rises in the energy range of 0.1 to $2.0 \mathrm{eV}$, that can be related to energy losses of at the grain boundaries and inter-granular silicon layers. ${ }^{24}$ This can be 
also explained by the decrease in the joint density of states due to the increase in the number of dangling bonds in the inter-crystallite layers. ${ }^{24}$

It is also observed that the small reflectance intensity is interpreted in terms of the defect density, disorder, crystalline/amorphous fraction and materials morphology, and it is mainly due to a longer optical path as the result of an efficient diffuse light scattering at the textured layer surface. ${ }^{25}$ The reflectance decreases due to the surface roughness especially in the $2 \sim 3 \mathrm{eV}$ range, which is demonstrated for $\mathrm{Zn}_{3} \mathrm{P}_{2} \cdot{ }^{26}$

The difference in the structural property of the silicide surface between $\mathrm{Mg}_{2} \mathrm{Si}$ and $\mathrm{Ca}_{2} \mathrm{Si}$ (or $\mathrm{Sr}_{2} \mathrm{Si}$ ) is observed in Refs.16-18. For the $\mathrm{Mg}_{2} \mathrm{Si}$ layer, the columnar domain structure along the growth direction is shown ${ }^{17}$. On the other hand, small granular domains with a size of $\sim 1 \mu \mathrm{m}$ are formed near the surface of the $\mathrm{Ca}_{2} \mathrm{Si}^{16}$ and $\mathrm{Sr}_{2} \mathrm{Si}$ layers. ${ }^{18}$ In addition, the surface roughness of $\mathrm{Ca}_{2} \mathrm{Si}$ and $\mathrm{Sr}_{2} \mathrm{Si}$ would be more degraded than that of $\mathrm{Mg}_{2} \mathrm{Si}$, because the $\mathrm{Ca}_{2} \mathrm{Si}$ and $\mathrm{Sr}_{2} \mathrm{Si}$ layers are formed by out diffusion and re-evaporation of the $\mathrm{Mg}$ atoms from the layers. ${ }^{16,18}$

The calculated values of band-gap for for $\mathrm{Mg}_{2} \mathrm{Si}, \mathrm{Ca}_{2} \mathrm{Si}$ and $\mathrm{Sr}_{2} \mathrm{Si}$ are estimated as 0.15 , 0.31 and $0.35 \mathrm{eV}$ using the first-principles total-energy calculation program based on LDA, respectively. These values should be underestimated because of the differences between the exchange-correlation matrix elements obtained by the LDA and GWA methods, and the neglect of the core-polarization interaction and to effects beyond the GWA. However, the calculated optical reflectance spectra agree well with the experimental ones in the higher energy range, which suggests the accuracy of the calculated electronic band diagrams for $\mathrm{Ca}_{2} \mathrm{Si}$ and $\mathrm{Sr}_{2} \mathrm{Si}$ within the slight underestimation of the calculated band gap. This report shows the first experimental optical evidence that $\mathrm{Ca}_{2} \mathrm{Si}$ and $\mathrm{Sr}_{2} \mathrm{Si}$ are narrow band gap semiconductors. Further investigation will be required to clarify their electronic structure and optical property.

\section{Conclusions}

The optical properties of single phase $\mathrm{M}_{2} \mathrm{Si}(\mathrm{M}=\mathrm{Mg}, \mathrm{Ca}$ and $\mathrm{Sr}$ ) silicides were characterized. The layers were grown by exposure of the $\mathrm{Si}$ and $\mathrm{Mg}_{2} \mathrm{Si} / \mathrm{Si}$ substrates to $\mathrm{Mg}$ and $\mathrm{Ca}$ (or Sr) fluxes, respectively. The experimental reflectance spectra of $\mathrm{Ca}_{2} \mathrm{Si}$ and $\mathrm{Sr}_{2} \mathrm{Si}$ were characterized for the first time. The experimental spectra well support the calculated electronic band diagrams within the possible underestimation of the band gap by the density functional calculation for the silicides. The optical property of the silicides is significantly affected by the morphological structural properties near the silicide surface. Further investigations will be required to clarify the optical property of the silicides. However, it is expected that the silicides may be candidates as new narrow gap semiconductors.

\section{References}

1. Y. Makita, in Mc Connel (Ed.), The First NREL Conference on Future Generation Photovoltaic Technologies, ed. R.D. McConnel (AIP, New York, 1997) pp. 3. 
2. M. Y. Au-Yang and M.L. Cohen, Phys. Rev. 178, 1358(1969); Solid State Commun. 6, 855(1968).

3. W. J. Scouler, Phys. Rev. 178, 1353(1969).

4. M. W. Heller and G. C. Damielson, J. Phys. Chem. Solid 23, 601(1962).

5. J.E.Mahan, A.Vantomme, G.Langouche and J.P.Becker, Phys.Rev.B54, 16965 (1996).

6. R. J. Labotz, D. R. Mason, D. F. O'kane, J. Electrochem. Soc. 110, 127(1963).

7. L. M. Zhang, Y. G. Leng, H. Y. Jiang, L. D. Chen, T. Hirai, Mater. Sci. Eng. B86, 195(2001).

8. B. Arnaud and M. Alouani, Phys. Rev. B62, 4464(2000); Phys. Rev. B64, 033202(2001).

9. O.Bisi, L.Braicovich, C.Carbone, I.Lindau, A.Iandelli, G.L.Olcese and A.Palenzona, Phys.Rev. B40, 10194(1989).

10. S. Lebègue, B. Arnaud, M. Alouani, and P. E. Bloechl, Phys. Rev. B67, 155208 (2003).

11. D.B. Migas, L. Miglio, V.L. Shaposhnikov and V.E. Borisenko, Phys. Rev. B67, 205203(2003).

12. Y. Imai, A. Watanabe, M. Mukaida, J. Alloys Compd. 358, 257(2003).

13. S. Lebègue, B. Arnaud and M. Alouani, Phys. Rev. B72, 085103(2005).

14. B.Eisenmann and H.Schafer, Z.Naturforsch.29B, 460(1974).

15. G. Nagorsen, G. Rocktaeschel, H. Schaefer, A. Weiss, Z. Naturforschung 22b, 101(1967).

16. T. Hosono, M. Kuramoto, Y. Matsuzawa, Y. Momose, Y. Maeda, T. Matsuyama, H. Tatsuoka, Y. Fukuda, S. Hashimoto, H. Kuwabara, Appl.Surf. Sci. 216, 620 (2003).

17. N. Takagi, Y. Sato, T. Matsuyama, H. Tatsuoka, M. Tanaka, C. Fengmin, H. Kuwabara, Appl. Surf. Sci. 244, 330(2005).

18. K. Miura, T. Ohishi, T. Inaba, Y. Mizuyoshi, N. Takagi, T. Matsuyama, Y. Momose, T. Koyama, Y. Hayakawa, H. Tatsuoka, Thin Solid Films 508, 74(2006).

19. A. Kato and H. Rikukawa, Phys. Rev. B 72 041101(R) (2005).

20. P. Hohenberg and W. Kohn, Phys. Rev. 136 B864(1964); W. Kohn and L. J. Sham, Phys. Rev. 140 A1133(1965).

21. C. Hartwigsen, S. Goedecker, and J. Hutter, Phys. Rev. B 58 3641(1998); S. Goedecker, M. Teter and J. Hutter, Phys. Rev. B 54 1703(1996).

22. G. Busch, P. Junod, U. Katz, and U. Winkler, Helv. Phys. Acta 27, 193(1954).

23. V.E. Borisenko, Semiconducting Silicides, Springer, 2000.

24. N.G. Galkin, S.V. Vavanova, A.M. Maslov, K.N. Galkin, A.V. Gerasimenko, T.A. Kaidalova, Thin Solid Films 515, 8230(2007).

25. A. Poruba, A. Fejfar, Z. Remeš, J. Špringer, M. Vaněček, J. Kočka, J. Meier, P. Torres and S. Shah, J. Appl. Phys. 88, 148(2000).

26. K. Jezierski and J. Misiewicz, Opt. Comm. 66, 217(1988). 